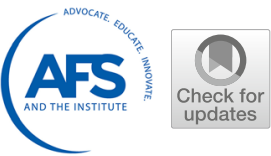

\title{
EFFECT OF ULTRASONIC VIBRATION TREATMENT ON MICROSTRUCTURE, TENSILE PROPERTIES, HARDNESS AND WEAR BEHAVIOUR OF BRASS ALLOY
}

\author{
M. E. Moussa $(1)$ and Khaled M. Ibrahim \\ Casting Technology Department, Manufacturing Technology Institute, Central Metallurgical R\&D Institute (CMRDI), \\ P.O. 87, Cairo, Egypt \\ M. Amin \\ Mechanical Engineering Department, Higher Technological Institute 10th of Ramadan City (HTI), 10th of Ramadan City, \\ Egypt
}

Copyright (c) 2022 The Author(s)

https://doi.org/10.1007/s40962-021-00748-8

\begin{abstract}
Effect of ultrasonic vibration (USV) treatment on microstructure and mechanical properties of brass alloy has been investigated. Microstructure of the investigated brass alloy without USV treatment exhibited stretched and dendritic $\alpha$-phase within an average length of $165 \mu \mathrm{m}$ and

The refinement of microstructure enhanced of course the mechanical properties of the brass alloy including yield strength, ultimate tensile strength, elongation, hardness and wear resistance. Furthermore, fracture surfaces and worn surfaces mechanisms were also discussed.
\end{abstract} also interdendritic coarse $\beta$-phase. By applying USV treatment, the $\alpha$-phase is significantly refined that obtained an average length of $21 \mu \mathrm{m}$. In addition, USV treatment achieved more homogenized structure of $\alpha$ and $\beta$-phases.
Keywords: casting, brass alloy, ultrasonic vibration, microstructure, grain refinement, wear

\section{Introduction}

Brass alloys are extensively used in many industrial products, such as bushes, bearings, valves connectors, pipes, heat exchangers, etc, due to their high corrosion resistance, high formability, and acceptable strength. ${ }^{1-3}$ Brass alloys can be classified according to their structure as: $\alpha, \alpha+\beta$ and $\beta$-brasses. ${ }^{3}$ For the cast brass, the microstructure contains denderitic structure of $\alpha$ solid solution, Widmanstätten structure of $\alpha+\beta$ and the hexagonal structure of $\beta .^{4}$

Under conventional casting process of brass alloys, the microstructure becomes coarse and heterogeneous, even when die casting process is used. That leads to the need for suitable liquid metal treatment to refine and modify the microstructure to exhibit an improvement in their mechanical properties. The addition of grain refiners to the melt is the most frequently used refinement technique due

Received: 18 July 2021 / Accepted: 13 December 2021 / Published online: 23 February 2022 to the high cooling rates that are not always applicable particularly when large thickness sections of casting are used or low thermal conductivity mould materials are used, such as sand and ceramic materials. However, the application of grain refiners leads to a fading effect over time. This can cause a less grain refining effect, especially in case of long-time interval between the additions of grain refiners and the pouring process. Furthermore, chemical grain refinement exhibits some dross within the melt that leads to difficulty in controlling the process. ${ }^{5}$ An addition of boron as a grain refiner for brass alloys led to formation of hard spots due to the formation of intermetallic compound. This will form due to the reaction between the boron with the iron existing in the brass alloy which cause comet tails and spoil at the surface finish of the cast during polishing. ${ }^{6}$

Referring to $\mathrm{Cu}-\mathrm{Zn}$ binary phase system, the optimum wear resistance can be achieved for $\mathrm{Zn}$ content of $25 \mathrm{wt} \%$. With an increase of $\mathrm{Zn}$ content to $48 \%$, there is an enhancement in hardness without further increase in wear performance. On the other hand, the lowest wear rate was 
obtained when the microstructure is composed of $\beta$-phase with about $25 \%$ of $\alpha$-phase located mainly at grain boundaries. ${ }^{7}$ Bouzayeni et al. ${ }^{8}$ studied the effect of different manufacturing processes of brass such as gravitational casting, casting under pressure, forging and freecutting on tribological properties. The results showed that gravitational casting had less wear resistance due to the presence of voids. By free-cutting the brass alloy, the material had a stabilized friction coefficient due to the uniform distribution of the various phases in the microstructure and the presence of a thick layer of metal transferred on the counter material.

Recently, refining and modifying the cast brass structure oriented into the ultrasonic vibration (USV) treatment has gained interest as an attractive process from both technological and economic viewpoints. ${ }^{9}$ Most publications have investigated the application of ultrasonic vibration (USV) treatment on medium melting point alloys such as $\mathrm{Al}$ and $\mathrm{Mg}$ based alloys for producing fine grain size, fine primary particles as well as modification of grain and primary particles morphology. ${ }^{10-18}$ Up to date, a smaller number of publications have explored the application of USV treatment on the cast structure of relatively high-melting point $\mathrm{Cu}$ based alloy. ${ }^{19,20}$ Therefore, this work introduced the effect of USV treatment on microstructure, tensile properties, hardness and wear behaviour of commercial brass alloy.

\section{Experimental Work}

\section{Melting and Processing}

Commercial brass alloy was melted using an electrical resistance furnace with graphite crucible of $8 \mathrm{~kg}$ capacity. Table 1 gives chemical composition of the investigated commercial brass alloy using an X-ray fluorescence (XRF) analyzer (model Axios advanced-PANALYTCAL). Firstly, the graphite crucible was prepared by heating it at $300{ }^{\circ} \mathrm{C}$ for $10 \mathrm{~min}$ in order to remove the moisture. After that, $5 \mathrm{~kg}$ brass alloy ingot was melted at about $1000{ }^{\circ} \mathrm{C}$ and held for 20 min with application of mechanical stirring by using a graphite rod for getting a full homogenization. Then, the melt surface was cleaned by removing the slag existing over the molten surface.

For applying USV treatment, the molten brass was poured into a preheated permanent cast iron mold $\left(200{ }^{\circ} \mathrm{C}\right)$ with

Table 1. Chemical Composition of the Investigated Brass Alloy (in wt\%)

\begin{tabular}{llllllll}
\hline $\mathrm{Cu}$ & $\mathrm{Zn}$ & $\mathrm{Pb}$ & $\mathrm{Sn}$ & $\mathrm{Mn}$ & $\mathrm{Fe}$ & $\mathrm{Ni}$ & $\mathrm{Al}$ \\
\hline Bal. & 38.6 & 1.61 & 0.438 & 0.673 & 0.487 & 0.221 & 0.502 \\
\hline
\end{tabular}

cylindrical shape having dimensions of $100 \mathrm{~mm}$ outer diameter, $42 \mathrm{~mm}$ inner diameter and $250 \mathrm{~mm}$ height. Figure 1 shows the position of mold that mounted on the sonotrode diameter of $40 \mathrm{~mm}$. The sonotrode probe protrudes approximately $20 \mathrm{~mm}$ into the bottom opening of the mold and creates the mold's bottom. The USV treatment was applied just before pouring with a fixed frequency 21.4 $\mathrm{KHz}$ at the highest output power of $4.2 \mathrm{KW}$ and continued till completing the solidification process. The pouring temperature of brass alloy was approximately $940{ }^{\circ} \mathrm{C}$ according to the previous work by Puga et al. ${ }^{19} \mathrm{He}$ concluded in his work that optimum temperature of ultrasonic treatment for brass alloy was $940{ }^{\circ} \mathrm{C}$ which leads to modification of microstructure. The Pouring temperature is controlled with an accuracy of about $2{ }^{\circ} \mathrm{C}$ using a high sensitivity type $\mathrm{K}$ thermocouple. In this work, the ultrasonic waves emitted from the transducer and passed through the acoustic sonotrode which transferred directly into the melt that poured into the mold during solidification process as shown in Figure 1. The melt became a part of acoustic sonotrode. Hence, the action of USV treatment on the brass alloy was raised remarkably. For comparison, a brass alloy without USV treatment was performed at the same condition.



Figure 1. Schematic of the experimental setup of applied USV treatment. 


\section{Materials Characterization}

For microstructure investigation, all investigated samples were cut from the bottom of each cast at a height of $30 \mathrm{~mm}$ from the sonotrode probe contact point. Figure 2 shows the positions of samples which are taken from castings for microstructure investigation and different tests. The investigated samples of microstructure were grinded and polished according to the standard procedures. Then, the specimens were etched by a solution mixture of $\mathrm{FeCl}(5 \mathrm{~g})$ $+\mathrm{HCl}(2 \mathrm{ml})+$ distilled water $(96 \mathrm{ml})$ for revealing the $\alpha$ and $\beta$-phases.

Optical microscope (OM) (model ZEISS) was used for studying the microstructure of the investigated samples. At a low magnification of $100 \times$, five micrographs were taken for each investigated specimen from the observed area. Image analyzer AxioVision SE64 Rel. 4.9 software was used to determine the size of $\alpha(\mathrm{Cu})$ grains. Energy dispersion spectrum (EDS) (model INCA PENTAFET X3) affiliated to the scanning electron microscope (SEM) (model JSMe5410) was used to determine the concentration of alloying elements in some selected areas at the microstructure.

In order to define the phases presented in the structure, $\mathrm{X}$-ray diffraction (XRD) (model X'PERT PRO) using $\mathrm{Cu}$ $\mathrm{k} \alpha$ radiation in step scan of $2 \theta$ from $20^{\circ}$ to $80^{\circ}$ with an increment of $0.02^{\circ}$ and a scanning speed of $4 \%$ min was also utilized.

\section{Tensile Test and Fractography Investigation}

Uniaxial tensile test was conducted at a strain rate of 0.25 $\mathrm{mm} / \mathrm{min}$ using a universal electronic tensile testing machine (model LFM-L-20KN, bench-top) at the room temperature. Three investigated specimens were taken

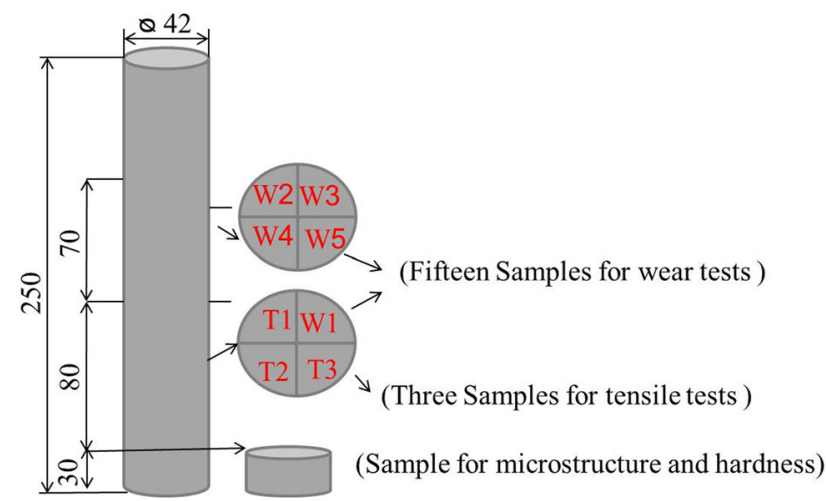

Figure 2. Simple positions for microstructure investigation and different tests of each cast (dimensions in $\mathrm{mm}$ ).

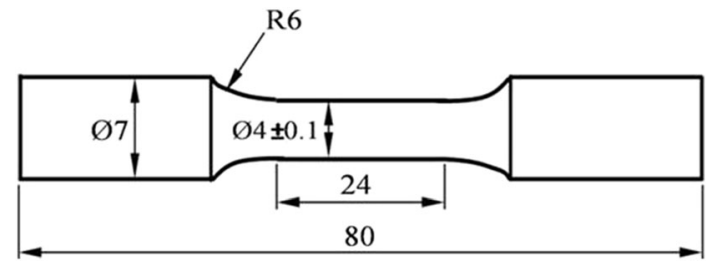

Figure 3. Dimensions of the tensile specimens (mm).

from the same position for each cast and machined them according to ASTM E8 standard, as shown in Figure 3. The average values of tensile properties in terms of yield strength, ultimate tensile strength (UTS) and elongation of the investigated brass castings without and with USV treatment was taken. SEM was also utilized to examine the fracture surfaces in order to determine the corresponding fracture mode.

\section{Hardness and Wear Tests}

Brinell hardness test was carried out for the investigated castings using the same samples of microstructure. A Brinell hardness tester (model INSTRON WOLPERT, TESTOR 971/3000) was used to determine the Brinell hardness values. The diameter ball indenter and an applied load were $5 \mathrm{~mm}$ and $250 \mathrm{Kgf}$, respectively. The mean of five successful measurements was considered for getting the hardness values.

Dry sliding wear test was carried out according to the ASTM G99-05 standard using pin-on-ring test machine (model TNO TRIBOMETER) at room temperature. The wear test specimens having a cylindrical shape with dimensions of $7 \mathrm{~mm}$ in diameter and $12 \mathrm{~mm}$ in height were machined out from the investigated castings which produced without and with USV treatment at the same position. The counter-face ring material was hardened ball bearing steel ring having hardness of $63 \mathrm{HRC}$ with dimensions of $73 \mathrm{~mm}$ in outer diameter. Prior to the wear test, surfaces of the investigated specimens and counterpart ring were grinded and polished, then ultrasonically cleaned for $15 \mathrm{~min}$ in acetone bath and air dried. Different applied loads of $(10,20,30,40,50 \mathrm{~N})$ at $10 \mathrm{~m} / \mathrm{s}$ constant sliding velocity for a testing period of $20 \mathrm{~min}$ were applied at ambient atmosphere. Three specimens were used for each condition of the wear test and the average value was taken. Before and after the wear test, the weights of the investigated specimens were determined using a precision balance with $0.1 \mathrm{mg}$ accuracy. The evolution of the wear rate was considered according to the loss of weight. SEM was also used to examine the worn surfaces in order to evaluate the corresponding mechanisms of wear. 


\section{Results and Discussion}

\section{Microstructure}

Figure 4 shows XRD patterns of the investigated brass alloy without and with USV treatment. XRD results reveal that the same phases of $\alpha$ and $\beta$-phases and $\mathrm{Pb}$ element presenting in the investigated brass alloy without and with USV treatment. therefore, there is no change in the obtained phases due to USV treatment.

Figure 5 displays microstructure of the investigated cast brass alloy prepared without and with USV treatment. Furthermore, Figure 6 shows the variation of average size of $\alpha-\mathrm{Cu}$ of the investigated brass alloy according to USV treatment. Without USV treatment, the microstructure exhibits elongated dendritic $\alpha$-phase with an average length of $165 \mu \mathrm{m}$ (Figure 6) and an interdendritic coarse $\beta$ phase, as shown in Figure 5a. Moreover, the morphology of this microstructure can be identified by classical Widmanstäetten structures. ${ }^{4,21}$

By applying USV treatment, $\alpha$-phase is significantly refined (Figure 5b) with an average length of $21 \mu \mathrm{m}$ (Figure 6). In addition, the structures of Widmanstäetten are less observable and there is random oriented of $\alpha$-phase as smaller plates and acicular-like morphology as shown in

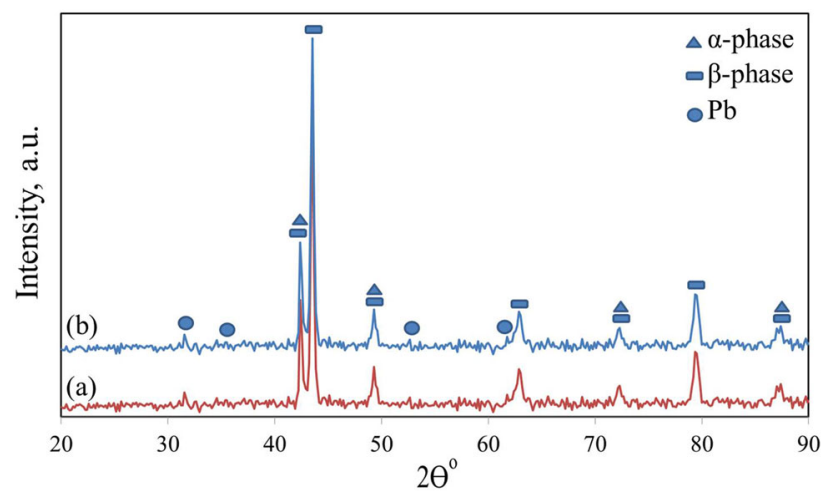

Figure 4. XRD patterns of the cast brass alloy (a) without USV (b) with USV treatment.
Figure 6b. Figures 7 and 8 show SEM micrographs with elemental mapping of the investigated brass alloy without and with applying USV treatment, respectively. $\alpha$ and $\beta$ phases become more homogenies (Figure 8) as compared to the sample without USV treatment (Figure 7).

In case of applying USV treatment, a lot of tiny bubbles were created in the melt when the alternating pressure reached above the cavitation threshold. These bubbles begin growing, then pulsing on a continuous expansion/compression regime and after that collapsing. ${ }^{11}$ In this work, two grain refinement mechanisms are coexist due to applying USV treatment during solidification process: (1) cavitation-enhanced heterogeneous nucleation followed by cavitation-induced dendrite fragmentation. Cavitation-enhanced heterogeneous nucleation is the dominated mechanism through the first stage of solidification process between pouring temperature of about $940{ }^{\circ} \mathrm{C}$ and the liquidus temperature of about $910{ }^{\circ} \mathrm{C}$ for the investigated brass alloy according to $\mathrm{Cu}-\mathrm{Zn}$ phase diagram. ${ }^{22}$ Since, the fragmentation of dendrites will not be possible at this temperature because solidification has not started yet.

The cavitation-enhanced heterogeneous nucleation mechanism can be further discussed by three different

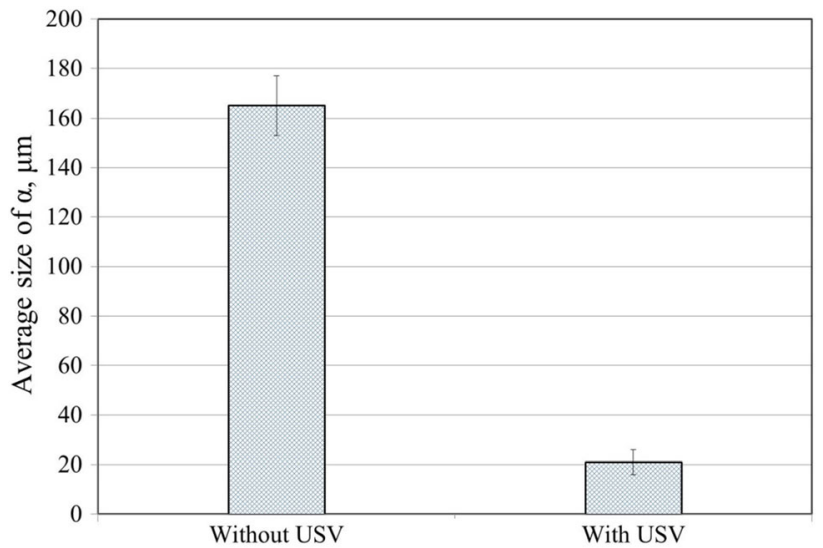

Figure 6. The average size of $\alpha-\mathrm{Cu}$ of the cast brass alloy without and with USV treatment.
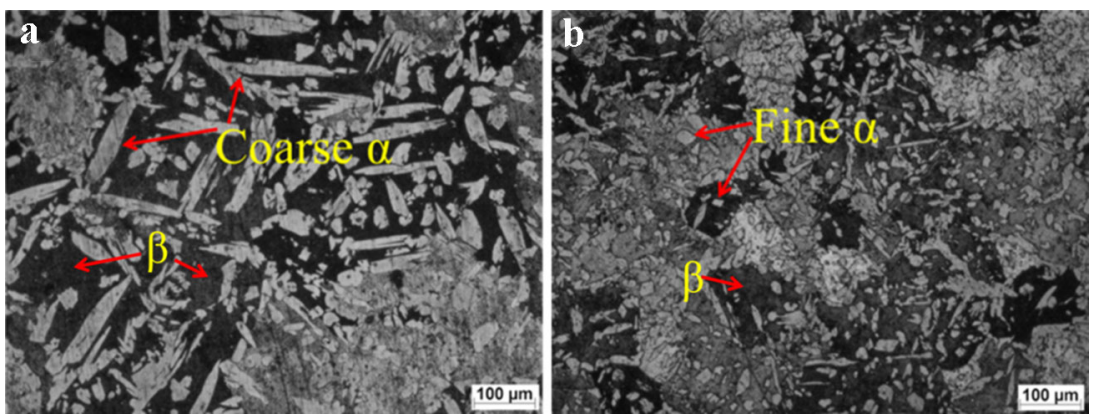

Figure 5. Microstructure of the investigated cast brass alloy (a) without USV and (b) with USV. 

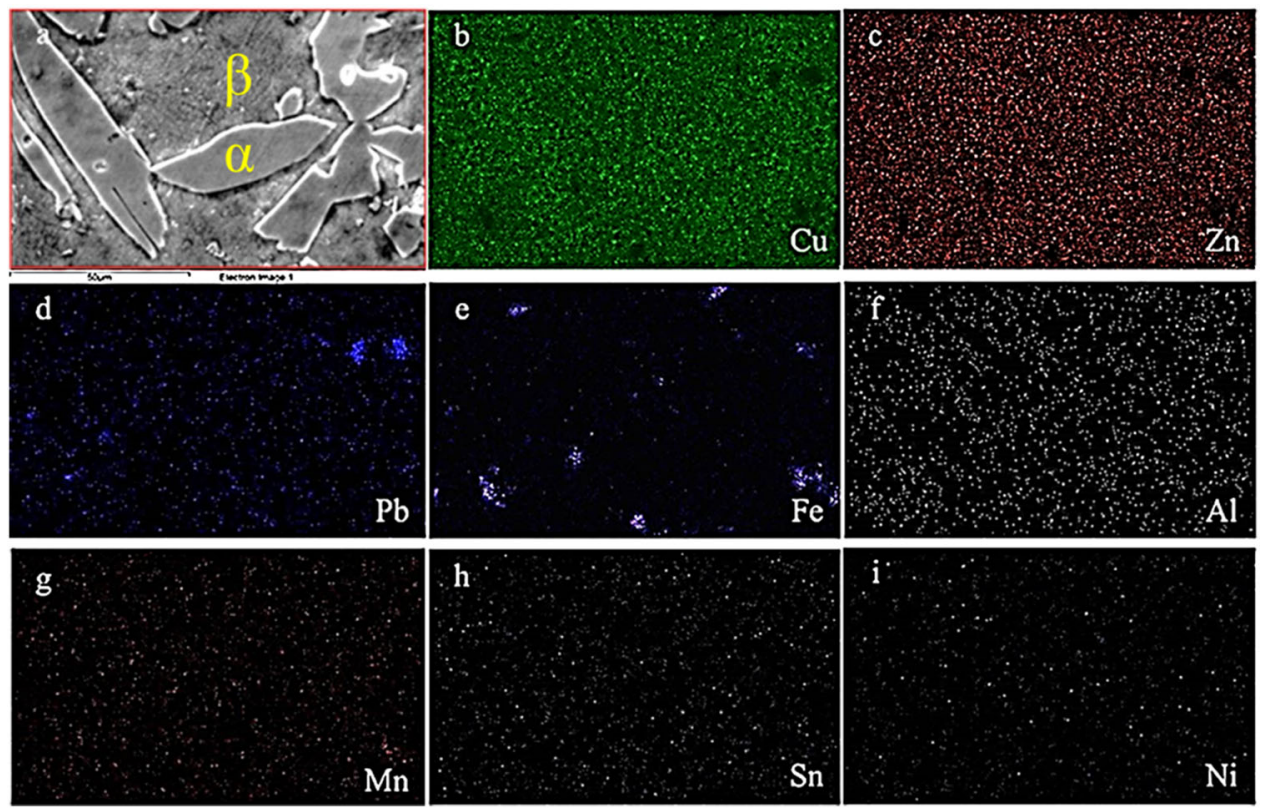

Figure 7. (a) SEM micrograph with elemental mapping of (b) $\mathrm{Cu}$, (c) $\mathrm{Zn}$, (d) $\mathrm{Pb}$, (e) $\mathrm{Fe}$, (f) Al, (g) Mn, (h) Sn and (i) Ni of the investigated brass alloy without USV treatment.


Figure 8. (a) SEM micrograph with elemental mapping of (b) $\mathrm{Cu}$, (c) $\mathrm{Zn}$, (d) $\mathrm{Pb}$, (e) $\mathrm{Fe}$, (f) $\mathrm{Al},(\mathrm{g}) \mathrm{Mn}$, (h) Sn and (i) Ni of the investigated brass alloy with USV treatment.

mechanisms. The first mechanism ${ }^{23}$ can be explained corroding to gas expansion inside the bubbles produced through cavitation which leads to undercool the liquid at the bubble/liquid interface and hence resulting in nucleation at the surfaces of bubbles. The second mechanism is related to the pressure pulse-melting point
(T) mechanism,,${ }^{13,18,24}$ so with increasing the pressure pulse due to collapsing bubbles leads to change of freezing point, $\mathrm{T}_{\mathrm{m}}$, based on Clausius-Clapeyron equation. Hence, with increasing $T_{\mathrm{m}}$, the undercooling will be increased so that the nucleation rate will be enhanced. The third mechanism is related to cavitation-enhanced wetting, ${ }^{14}$ which assumes 
that the pressure pulse generated from the bubbles collapsing produced large energy in the melt which leads to insoluble non-metallic inclusions that can be wetted by the melt. Hence these substrates formed active nuclei in the process of solidification which enhancing the heterogeneous nucleation upon the low undercooling. The first mechanism only takes place through the expansion stage of bubbles, while the other mechanisms required the collapsing of bubbles.

Below the liquidus temperature, the dominated refinement mechanism is cavitation-induced dendrite fragmentation. This mechanism assumes that collapse of bubbles generates shock waves leads to dendrites fragmentation, 8,24 which are re-distributed during acoustic streaming. both mechanisms of cavitation-enhanced heterogeneous nucleation and cavitation-induced dendrite fragmentation can produce large numbers of nuclei in the melt. Hence, the microstructure of the investigated brass alloy is significantly refined and more homogenize of $\alpha$ and $\beta$-phases can be achieved.

\section{Mechanical Properties}

Figure 9 illustrates tensile properties in terms of yield strength, ultimate tensile strength (UTS) and elongation of the investigated brass castings without and with USV treatment. Figure 10 shows also Brinell hardness of the investigated brass alloy without and with USV treatment. It is clear that USV treatment has a significant effect on improvement tensile properties and hardness of the investigated brass alloy. Average yield strength, UTS, elongation and hardness increased from $190 \mathrm{MPa}, 373 \mathrm{MPa}, 5 \%$ and $70 \mathrm{HB}$ without USV treatment to $225 \mathrm{MPa}, 433 \mathrm{MPa}$, $8 \%$ and $79 \mathrm{HB}$ with USV treatment, respectively. Generally speaking, mechanical properties of engineering alloys are improved with the refinement of their microstructure. ${ }^{25}$ Furthermore, it has been reported that tensile strength and hardness of alloys are related to grain size according to Hall-Petch equation. ${ }^{26,27}$ From the scope of dislocation pile-up model according to Hall-Petch equation, the refinement of grains leads to increase the number of grain boundaries which acts as barriers for impeding dislocations movement. These dislocations pile up at grain boundaries strengthening the metallic alloys. ${ }^{27}$ Therefore, the hardness and tensile strength of alloys improved with reduction of grain size. Hence, it can be deduced here that the enhancement of hardness and tensile properties of the investigated ultrasonic treated brass alloy is related to the refinement of $\alpha$ solid solution with shorter plates and acicular morphology and also less perceptible Widmanstäetten structure.

Figure 11 displays fracture surfaces of tensile specimens of the investigated cast brass alloy without and with USV treatment, respectively. Without USV treatment, the fracture surface exhibited some tear ridges and cleavage facets. This means the quasi-cleavage fracture is the dominated mechanism (Figure 11a). With USV treatment, some small dimples are observed on the fracture surface. This means a ductile fracture is the dominated mechanism (Figure 11b).

Figure 12 represents the weight loss of the investigated cast brass alloy without and with USV treatment at different applied loads. It can be found that the weight loss of the ultrasonic treated alloy is less than that of the untreated alloy. However, the weight loss increases with increasing the applied loads due to increasing the shear stress over the worn surface. This improvement of wear resistance of



Figure 10. Brinell hardness of cast brass alloy without and with USV treatment.
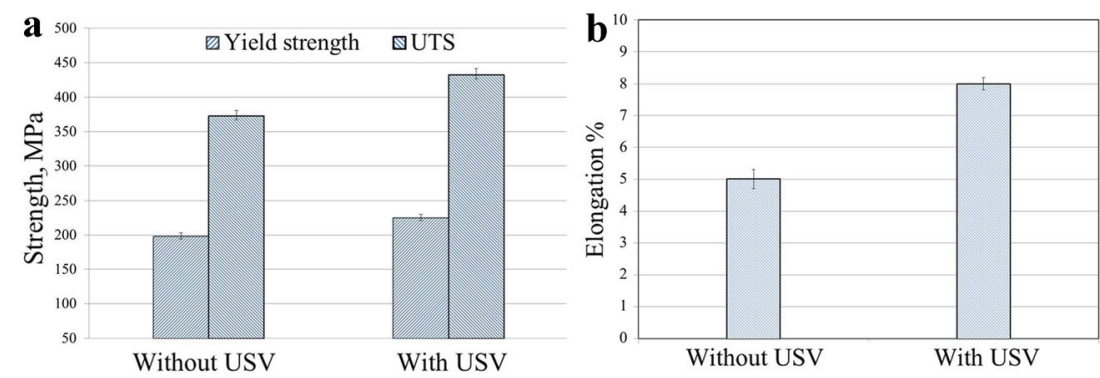

Figure 9. Tensile properties of cast brass alloy without and with USV treatment: (a) Ultimate tensile strength and (b) elongation \%. 


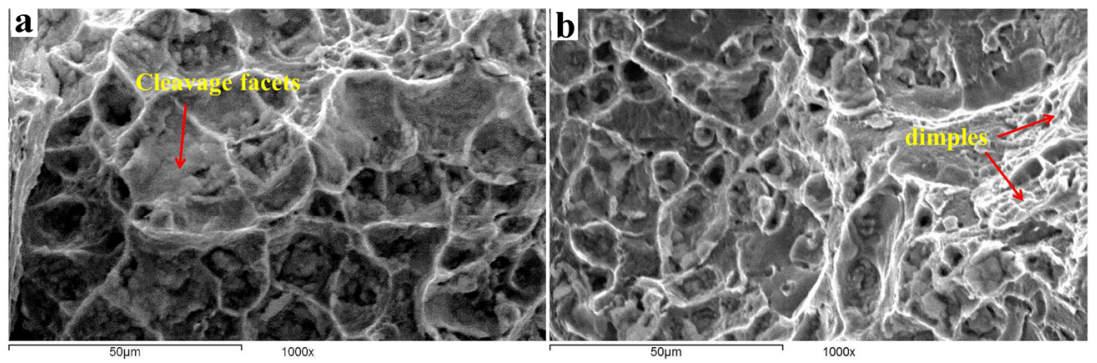

Figure 11. Fracture surface morphologies of tensile specimens of the cast brass alloy (a) without and (b) with USV treatment.

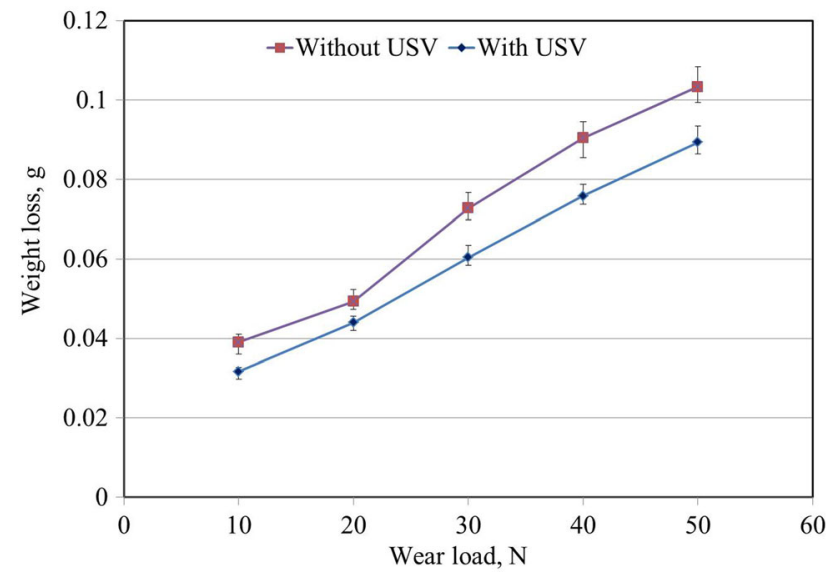

Figure 12. Effect of USV treatment on weight loss of cast brass alloy. ultrasonic treated brass alloy can be attributed to the influence of microstructure refinement and high hardness of the investigated brass alloy obtained by USV treatment. The wear resistance of a polycrystalline material is increased with increasing its hardness according to Archard's equation. ${ }^{28}$ Hence, the enhancement in the resistance to wear of the ultrasonic treated brass alloy is related to increase in its hardness as compared with the untreated alloy.

Figure 13 shows the worn surfaces of cast brass alloy without and with USV treatment at low and high applied loads. At low applied load of $10 \mathrm{~N}$, the worn surfaces exhibited shallow scratches and spalling of wear particles, indicating the dominated wear mechanism is mild delamination wear with little adhesion (Figure 13a, c). Some cracks are observed on the large primary $\alpha-\mathrm{Cu}$ phase for the untreated brass alloy (Figure 13a). The weight loss decreased for the ultrasonic treated brass alloy (Figure 13c)
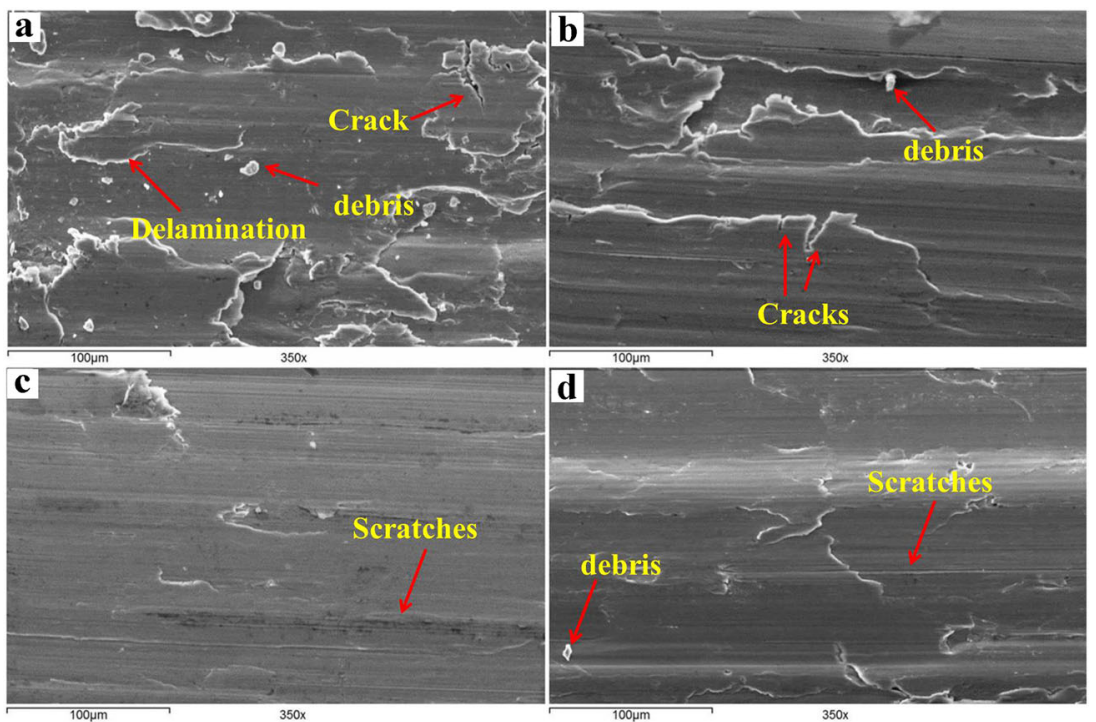

Figure 13. SEM micrograph of worn surface of the cast brass alloy without and with USV treatment at different applied loads; (a) $10 \mathrm{~N}$ without USV, (b) $50 \mathrm{~N}$ without USV, (c) $10 \mathrm{~N}$ with USV, and (d) $50 \mathrm{~N}$ with USV. 
in terms of reduction of scratches over the worn surface which is related to its refinement of microstructure and high hardness. In case of high applied load of $50 \mathrm{~N}$, the worn surfaces exhibited a combination of plastic deformation and spalling of wear particles which indicated to the operating wear mechanism is a combination of adhesive and delamination wear mechanisms (Figure 13b, d). Moreover, some of cracks, intense plastic deformation and severe spalling are observed on the worn surface for the investigated brass alloy without USV treatment (Figure 13b) as compared to the ultrasonic treated brass alloy (Figure 13d) due to the influence of microstructure refinement and high hardness of the investigated brass alloy obtained by USV treatment. It was published that the improvement in the wear resistance of brasses is related to the increase in hardness. This is due to micro-cutting and micro-plowing mechanisms that are responsible for material removal from the surface. ${ }^{29}$ By applying high loads, the operating wear mechanisms will be the combination of adhesive and delamination wear. Delamination wear observed through subsurface deformation, nucleation and propagation of crack, respectively which exhibited the spalling of wear debris above the worn surface. ${ }^{30}$ So, the behaviors of wear at high applied loads are basically considered as the nucleation and propagation of subsurface cracks. Third-body abrasion is also considered due to the spalling of wear particles which leads to easy removing the material which adhering on the worn surface. ${ }^{31,32}$

\section{Conclusions}

1. USV treatment has a significant effect on microstructure refinement of the investigated cast brass alloy during solidification stages.

2. Two grain refinement mechanisms coexist by conducting USV treatment: cavitation-enhanced heterogeneous nucleation followed by cavitationinduced dendrite fragmentation.

3. USV treatment has a significant effect on enhancement of tensile properties, hardness and wear resistance of the investigated cast brass alloy.

4. Tensile fracture surfaces changed from quasicleavage to ductile by conducting USV treatment.

5. Wear mechanism at low applied load was mild delamination wear with little adhesion.

6 Wear mechanism at high applied load was a combination of adhesive and delamination wear as well as third-body abrasion mechanism.

\section{Acknowledgements}

The authors would like to thank Central Metallurgical R\&D Institute for funding this research work.

\section{Funding}

Open access funding provided by The Science, Technology \& Innovation Funding Authority (STDF) in cooperation with The Egyptian Knowledge Bank (EKB).

\section{Open Access}

This article is licensed under a Creative Commons Attribution 4.0 International License, which permits use, sharing, adaptation, distribution and reproduction in any medium or format, as long as you give appropriate credit to the original author(s) and the source, provide a link to the Creative Commons licence, and indicate if changes were made. The images or other third party material in this article are included in the article's Creative Commons licence, unless indicated otherwise in a credit line to the material. If material is not included in the article's Creative Commons licence and your intended use is not permitted by statutory regulation or exceeds the permitted use, you will need to obtain permission directly from the copyright holder. To view a copy of this licence, visit http://creativecommons.org/ licenses $/$ by $/ 4.0 /$.

\section{REFERENCES}

1. I. Dinaharan, S. Karpagarajan, R. Palanivel, J.D.R. Selvam, Microstructure and sliding wear behavior of fly ash reinforced dual phase brass surface composites synthesized through friction stir processing. Mater. Chem. Phys. 263, 124430 (2021). https://doi.org/10. 1016/j.matchemphys.2021.124430

2. H.S. Kim, W.Y. Kim, K.H. Song, Effect of post-heattreatment in ECAP processed $\mathrm{Cu}-40 \% \mathrm{Zn}$ brass.

J. Alloys Compd. 536, S200-S203 (2012). https://doi. org/10.1016/j.jallcom.2011.11.079

3. E.R. Bagherian, Y. Fan, A. Abdolvand, M. Cooper, B. Frame, Investigation of the distribution of lead in three different combinations of brass feedstock. Inter Metalcast 10, 322-328 (2016). https://doi.org/10.1007/ s40962-016-0055-1

4. H. Chih-Chun, W. Jia-Siang, W.P. Ti-Yuan, W. Weite, Microstructure development of brass alloys with various $\mathrm{Bi}$ and $\mathrm{Pb}$ additions. Met. Mater. Int. 19, 1173-1179 (2013). https://doi.org/10.1007/s12540013-6002-2

5. M. Sadayappan, D. Cousineau, R. Zavadil, M. Sahoo, H. Michels, Grain refinement of permanent mold cast copper-base alloy. AFS Trans. 110, 505-514 (2002)

6. M. Sadayappan, R. Zavadil, R. Packwood, M. Sahoo, H. Michels, Hard spot formation in grain refined yellow brass and EnviroBrass III. AFS Trans. 111, 407-415 (2003) 
7. H. Mindivan, H. Çimenoğlu, E.S. Kayali, Microstructures and wear properties of brass synchroniser rings. Wear 254, 532-537 (2003)

8. N. Bouzayeni, V.S. Aigbodion, M. Kchaou, R. Elleuch, Comparative study of the tribological behavior of brass alloys produced by different manufacturing processes. J Fail. Anal. Prev. 13, 584-594 (2013)

9. X. Chen, C. Yin, Q. Le, S. Ning, F. Yu, The microstructure refinement and strength enhancement of $\mathrm{Mg}-\mathrm{Al}-\mathrm{Si}$ alloy subjected by alternating-frequency ultrasonic melt treatment. Int. J. Metalcast. (2021). https://doi.org/10.1007/s40962-021-00623-6

10. W. Khalifa, S. El-Hadad, Ultrasonication effects on the microstructure characteristics of the A380 die cast alloy. Int. J. Metalcast. 13, 865-879 (2019). https:// doi.org/10.1007/s40962-018-00296-8

11. G.I. Eskin, Broad prospects for commercial application of the ultrasonic (cavitation) melt treatment of light alloys. Ultrason. Sonochem. 8, 319-325 (2001). https://doi.org/10.1016/S1350-4177(00)00074-2

12. M.E. Moussa, M.A. Waly, A.M. El-Sheikh, Combined effect of high-intensity ultrasonic treatment and $\mathrm{Ca}$ addition on modification of primary $\mathrm{Mg}_{2} \mathrm{Si}$ and wear resistance in hypereutectic $\mathrm{Mg}-\mathrm{Si}$ alloys. J. Alloys Compd. 615, 576-581 (2014). https://doi.org/10.1016/ j.jallcom.2014.06.154

13. M.E. Moussa, M.A. Waly, A.M. El-Sheikh, Effect of high-intensity ultrasonic treatment on modification of primary $\mathrm{Mg}_{2} \mathrm{Si}$ in the hypereutectic $\mathrm{Mg}-\mathrm{Si}$ alloys. J. Alloys Compd. 577, 693-700 (2013). https://doi. org/10.1016/j.jallcom.2013.06.189

14. B. Patel, G.P. Chaudhari, P.P. Bhingole, Microstructural evolution in ultrasonicated AS41 magnesium alloy. Mater. Lett. 66, 335-338 (2012)

15. M.K. Aghayani, B. Niroumand, Effects of ultrasonic treatment on microstructureand tensile strength of AZ91 magnesium alloy. J. Alloys Compd. 509, 114-122 (2011)

16. T.V. Atamaneko, D.G. Eskin, L. Zhang, L. Katgerman, Criteria of grain refinement induced by ultrasonic melt treatment of aluminum alloys containing $\mathrm{Zr}$ and Ti. Mater. Trans. A 41, 2056-2066 (2010)

17. X. Liu, Y. Osawa, S. Takamori, T. Mukai, Grain refinement of AZ91 alloy by introducing ultrasonic vibration during solidification. Mater. Lett. 62, 2872-2875 (2008)

18. A. Ramirez, M. Qian, B. Davis, D.H. StJohn, Potency of high-intensity ultrasonic treatment for grain refinement of magnesium alloys. Scr. Mater. 59, 19-22 (2008)

19. H. Puga, J. Barbosa, J.M. Machado, C. Vilarinho, Ultrasonic grain refinement of die cast copper alloys. J. Mater. Proc. Tech. 263, 336-342 (2019). https://doi. org/10.1016/j.jmatprotec.2018.08.034
20. M.E. Moussa, M.A. Waly, M. Amin, Effect of high intensity ultrasonic treatment on microstructural modification and hardness of a nickel-aluminum bronze alloy. J. Alloys Compd. 741, 804-813 (2018)

21. N. Stanford, P.S. Bate, Crystallographic variant selection in $\alpha-\beta$ brass. Acta Mater. 53, 859-867 (2005). https://doi.org/10.1016/j.actamat.2004.10.043

22. Massalski, T.B., Binary Alloy Phase Diagrams (ASM International, 1986), p. 981

23. X. Jian, H. Xu, T.T. Meek, Q. Han, Effect of power ultrasound on solidification of aluminum A356 alloy. Mater. Lett. 59, 190-193 (2005)

24. P.P. Bhingole, G.P. Chaudhari, Synergy of nano carbon black inoculation and high intensity ultrasonic processing in cast magnesium alloys. Mater. Sci. Eng. A 556, 954-961 (2012)

25. M.E. Moussa, M.A. Waly, A.M. El-Sheikh, Effect of $\mathrm{Ca}$ addition on modification of primary $\mathrm{Mg}_{2} \mathrm{Si}$, hardness and wear behavior in $\mathrm{Mg}_{2} \mathrm{Si}$ hypereutectic alloys. J. Magn. Alloys 2, 230-238 (2014)

26. J. Yang, B.L. Xiao, D. Wang, Z.Y. Ma, Effects of heat input on tensile properties and fracture behavior of friction stir welded $\mathrm{Mg}-3 \mathrm{Al}-1 \mathrm{Zn}$ alloy. Mater. Sci. Eng. A 527, 708-717 (2010)

27. R.R. Baracaldo, J.M.C. Marrero, J.A.B. Páramo, Studying the Hall-Petch effect regarding sub-micrometer steel $(0.6 \%$ C). Ingeniería e Investigación 31, 112-122 (2011)

28. H.S. Kim, W.Y. Kim, K.H. Song, Effect of post-heattreatment in ECAP processed $\mathrm{Cu}-40 \% \mathrm{Zn}$ brass.

J. Alloys Compd. 536, S200-S203 (2012). https://doi. org/10.1016/j.jallcom.2011.11.079

29. J. Xia, C.X. Li, H. Dong, Thermal oxidation treatment of B2 iron aluminide for improved wear resistance.

Wear 258, 1804-1812 (2005). https://doi.org/10.1016/ j.wear.2004.12.016

30. J. Zhang, A.T. Alpas, Delamination wear in ductile materials containing second phase particles. Mater. Sci. Eng. A 160, 25-35 (1993). https://doi.org/10. 1016/0921-5093(93)90494-Y

31. K.J. Jin, Z.H. Qiao, S.Y. Zhu, J. Cheng, B. Yin, J. Yang, Friction and wear properties and mechanism of Bronze-Cr-Ag composites under dry-sliding conditions. Tribol. Int. 69, 132-140 (2016). https://doi.org/ 10.1016/j.triboint.2015.12.031

32. L. Ceschini, C. Bosi, A. Casagrande, G.L. Garagnani, Effect of thermal treatment and recycling on the tribological behaviour of an AlSiMg-SiCp composite. Wear 251, 1377 (2001). https://doi.org/10.1016/ S0043-1648(01)00782-7

Publisher's Note Springer Nature remains neutral with regard to jurisdictional claims in published maps and institutional affiliations. 